You mentioned earlier that you'd only been to Edinburgh, prior to taking the Chair at the Untwersity, on your way to Wester Ross. Are you still walking, climbing, playing squash?

Yes, but I had to give up playing squash about three years ago. My knees ceased turning corners when the rest of me turned. But I still walk and climb. I spent my holiday this summer trekking in the Hindu Kush. It was quite hard work, but I felt much better for having had some fresh air and exercise. Sitting at a desk all day long doesn't suit me.

\title{
A piece of his mind
}

He is a kind man, a caring physician, who strove hard to help the children who had psychiatric problems; although the successes were hard won, the gratitude of the children and their parents more than made up for the long hours of work.

Not all of the patients could be cured, those with autism or severe behaviour disorders, and the children from inadequate families, but common sense and practical approaches would help to modify some of the daily problems.

Teachers and nurses, activity therapists, doctors and social workers worked together as a team, using their special skills to help these difficult children. Kindness and consistency, laughter and physical activity, learning and living together, were the most important parts of the treatment. These were the skills that he taught and used.

Now a cruel stroke of fate is robbing this man of his very self, as the relentless progression of Alzheimer's syndrome steals his mind. He loved to read the great authors, to listen to fine music, to plant trees to enrich the soil and save the environment.

This man who raised three children, and counted them as his best friends, who trained countless physicians and nurses and all the other team members, is now losing the very core of his being.

It is time for him to be the recipient of the love, care, patience, training and encouragement that he so liberally gave to others.

Just as for some of the children there was no cure, so there is no cure for him.

He knows what is happening and in his quiet and proud way, strives to live his life with dignity, keeping to himself the fears and difficulties for the most part. The frustration at taking long minutes to write a few words, always spelt correctly, although the letters and their making cannot be recalled without huge effort.

Reading books that he loves, only to find that the memory from one moment to the next is lost. Listening to music, a joy still to be savoured, bringing peace and calm to his muddied mind.

Just as the troubled children are lost in the task of living in this complex world, so this kind man is lost. But he knew where he was going until the cruel amyloid plaques invaded the brain, muddying the paths and twisting the thought process. To be a psychiatrist and make the diagnosis of Alzheimer's on oneself, would seem to be too much to bear.

The burden of the disease is shared by his whole family, and as the changes come, so they have to learn the great lesson of living each day to its fullest. Memories are always there, happy ones to be remembered and laughed over, the sad and the serious moments diluted by their very age, recalling long forgotten moments of happy times. Friends and colleagues assume new and greater importance, the friends from the past reaching out with letters and visits and acceptance of the turn of events. Colleagues, alas are often too busy looking after other patients to be able to spare the time for a much needed friendship at this difficult time.

Such are the tricks of fate dealt to one. It is a challenge to test the endurance and imagination of us all. Whether to sink under the load, or to find the hidden strengths with which to grow and flourish in the face of adversity. Just as the thousands of trees that he planted, grew in strength and beauty, weathering the drought and heat and icy cold of many years, maturing into a great and lovely forest. 